\title{
IP David: Casebook of orthopaedic rehabilitation
}

\section{Springer, Heidelberg, Berlin, 2008, 342 pp; 74 figs, €34.95 (net price) CHF 61,00, ISBN 978-3-540-74426-9 (Softcover)}

\author{
Pierre Kehr
}

Received: 16 August 2009/Accepted: 18 August 2009/Published online: 1 September 2009

(C) Springer-Verlag 2009

The author informs us of his experiment of alternative methods of readjustment in very specific cases. The field of experimentation is very broad, of the taïchi to the virtual reality, while passing by hypergravity stimulation therapy. The book is divided into two parts: section I, containing 39 clinical case reports, and section II general introduction and real life applications.

This work is very surprising both in its content as well as in its form. Indeed, the author starts from heterogeneous clinical cases with the most varied affections, for which are decided unusual treatments. Can one generalize starting from specific cases? Scientifically speaking, the answer is negative. This anachronistic work in its methodology, is thus justified only like starting point with reflections or possible future studies, in order to validate and to evaluate the reproductiveness of the results.

Recommended to those who do not find traditional answers to their therapeutic interrogation.

No funds were received in support of this study.

Laurent Balabaud Paris

P. Kehr $(\bowtie)$ 